\title{
N

\section{O direito educacional ao ensino primário nas relações do agir comunicativo do Estado em face da sociedade na Província do Pará}

The educational right to primary education in the relations of the communicative action of the State in the face of society in the Province of Pará

\author{
* Paulo Sérgio de Almeida Corrêa \\ Professor doutor na Universidade Federal do Pará, Belém, Pará, Brasil. \\ paulosac@ufpa.br - https://orcid.org/0000-0002-9975-9919 \\ ** Renato Pinheiro da Costa \\ Professor doutor na Universidade Federal do Pará, Belém, Pará, Brasil. \\ renatopc@ufpa.br
}

Recebido em 02 de novembro de 2018

Aprovado em 29 de julho de 2019

Publicado em 11 de setembro de 2019

\section{RESUMO}

O presente estudo objetivou identificar as relações estabelecidas entre os sujeitos sociais e o Estado, por meio da comunicação ocorrida através da linguagem empregada nos textos legislativos dos presidentes da Província do Estado do Pará, à época do período imperial. Quais os mecanismos acionados pela sociedade para ter acesso ao direito educacional nas vilas do interior da então Província do Pará, durante o período imperial? Realizou-se pesquisa bibliográfica e documental concernente ao século XIX. Além de instituir sua interferência na sociedade a partir das regras jurídicas, o Estado brasileiro e suas Províncias, na fase imperial, também faziam circular as normas regulamentadoras por meio dos jornais, relatórios, a imprensa, na organização e funcionamento curricular, na seleção dos conhecimentos oficiais ensinados nas instituições escolares, e pela inspeção e controle sobre o trabalho dos professores, de modo a incluir o outro na teia discursiva baseada na racionalidade das ações públicas e da forma como se efetiva a distribuição dos papeis sociais, principalmente tendo a oferta do direito à educação e o acesso às Escolas de Primeiras Letras como suas premissas na concessão de privilégios e imposição de deveres.

Palavras-chave: Estado e sociedade; Província do Pará; Direito à educação. 


\section{Autuaŗão}

ISSN: 1984-6444 | http://dx.doi.org/10.5902/1984644435456

\section{ABSTRACT}

The present study aimed to identify the relations established between social subjects and the State, through the communication occurred through the language used in the legislative texts of the presidents of the State of Pará, at the time of the imperial period. What are the mechanisms used by society to have access to educational law in the villages of the interior of the then Pará Province during the imperial period? Bibliographical and documentary research concerning the nineteenth century was carried out. In addition to instituting their interference in society from the legal rules, the Brazilian State and its Provinces, in the imperial phase, also circulated the regulatory norms through newspaper, reports, the press, in the organization and curricular functioning, in the selection of knowledge officials taught in school institutions, and by inspections and control over the work of teachers, so as to include the other in the discursive we based on the rationality of public actions and the way the distribution of social roles is effected, especially with the provision of the right education and access to the First Letter Schools as their premises in the granting of privileges and the imposition of duties.

Keywords: State and society; Province of Pará; Right to education.

\section{Introdução}

Discute-se neste artigo as estratégias configuradoras do agir comunicativo adotado pelo Estado, em face da luta empreendida pela sociedade na Província do Pará, a fim de assegurar o direito educacional ao ensino primário.

Embora as regras jurídicas constituíssem uma das formas principais de intervenção do Estado na vida pública e privada, os jornais, relatórios, a atuação da imprensa, os modos de organização do currículo e os processos de seleção dos conhecimentos oficiais difundidos nas escolas, bem como o controle exercido sobre $o$ trabalho docente, igualmente integravam a teia discursiva da racionalidade das ações públicas envolvendo a oferta e acesso às Escolas de Primeiras Letras.

Sobre o Estado moderno, é importante destacar que "Assim como toda sociedade, o Estado também é uma estrutura dinâmica e que sofre alterações no decorrer da História" (OLIVEIRA, 2006, p. 547). Além disso:

Destaca-se na formação do Estado Moderno o estabelecimento de uma administração burocrática racional. Na verdade, no Estado Absoluto, essa burocracia era peculiar, pois era considerada como uma mercadoria, o cargo era comprado. Com a racionalização, crescente, a função do funcionário passou a ser regulada a partir da legitimidade das regulamentações legais (OLIVEIRA, 2006, p. 548). 


\section{F HWM entubará

ISSN: 1984-6444 | http://dx.doi.org/10.5902/1984644435456

A dinâmica em que a educação se desenvolveu ao longo dos séculos, torna evidente que sua história é uma construção que aos poucos foi produzida a partir das questões demandadas da parte do Estado e dos sujeitos sociais envolvidos, e a incapacidade de registrar os acontecimentos ocorridos nesse processo, fez com que muitos fatos ficassem ocultos, por isso o estudo da historiografia é de suma importância nas pesquisas educacionais, conforme investigações já desenvolvidas por Saviani (2005), e Zotti (2006).

Tratando-se da formação e consolidação do Estado brasileiro, no período de 1808-1889, Alves Filho (2009, p. 102-107) considerou haver "mecanismos políticos e administrativos", bem como "certas características estruturais forjadas ao longo do nosso processo histórico" que marcam a identidade nacional brasileira, dentre as quais estão: a Independência como processo de rompimento paulatino e gradual; a formação do Estado Nacional Brasileiro a partir de 1822, bem como sua consolidação no período do segundo reinado de 1840-1889. Por outro lado, destaca:

Diferente do que ocorreu nas nações latino-americanas colonizadas pela Espanha, no Brasil, o processo de independência não conduziu a imediata proclamação da República, mas sim à constituição do País como Império. E é sob a égide de Governos imperiais que se formou e consolidou o Estado Nacional (ALVES FILHO, 2009, p. 109).

Percebe-se que, tanto no contexto nacional, quanto no âmbito das suas frações provinciais, o Estado Moderno assumiu forma política específica no Brasil, com desdobramentos peculiares em cada espaço territorial por onde lançava seus espectros.

Muito embora já se disponha de muitas pesquisas sobre essa área de conhecimento, como aponta Corrêa (2013, p. 79), ainda há questões a serem elucidadas, daí o empenho em investigar a temática sobre a regulamentação do ensino primário no período do Segundo Império, por meio das promessas apresentadas a partir da legislação educacional, concentrando a evidência de seu acontecimento no interior da Província do Pará, mais especificamente na então Vila de Moju ${ }^{1}$.

O interesse por este trabalho emergiu com intuito de contribuir com a discussão no campo da história da educação, trazendo para o debate a lógica que os fatos 


\section{Authabูão}

ISSN: 1984-6444 | http://dx.doi.org/10.5902/1984644435456

históricos são produzidos sob uma base ideológica, epistemológica e cultural. Neste caso a linguagem se constitui um campo muito promissor para a produção da história, pois, a cada período o conjunto social se debruça sobre uma tradição cultural, um discurso ideológico predominante, a um enredo que faz com que todos sejam envolvidos pela rede discursiva.

Este trabalho, tratando-se das relações de uma sociedade do século XIX, vem demonstrar que, no espectro de atuação do Estado, existem mecanismos que a população precisa assimilar e participar se quiser ser atendida em algumas de suas reivindicações. Neste sentido Habermas (2000, p. 529) diz que: "Sistemas sociais elaboram o sentido na forma da comunicação. Para esse fim, faz-se uso da linguagem. Mas esta não fornece expressões de significado idêntico, apenas permite substituir por signos o sentido".

Procurando desenvolver este trabalho com base na premissa de que existe um enredo envolvendo as sociedades na produção da história, estruturou-se esta investigação tomando como local da pesquisa a atual cidade de Moju, no período correspondente ao Segundo Império, época de vigência da Província do Pará.

Para tanto, formulou-se o seguinte problema de pesquisa: Quais os mecanismos acionados pela sociedade para ter acesso ao direito educacional nas vilas do interior da então Província do Pará, durante o período imperial?

Desse modo, este trabalho objetivou identificar a relação estabelecida entre os sujeitos sociais e o Estado no desenvolvimento da comunicação ocorrida por meio do domínio da linguagem estabelecida nas prerrogativas normativas sancionadas para o setor da educação, através das legislações e despachos do presidente da Província do Pará, à época do período imperial.

Metodologicamente, realizou-se a pesquisa bibliográfica, recurso que possibilitou inferir, com estudo de autores que discutem o desenvolvimento do sistema social em meio às mobilizações do movimento da modernidade e seu envolvimento com a formação do Estado, bem como foram consultadas e analisadas fontes documentais relacionadas à legislação do período imperial, relatórios de presidentes de Província e jornais da época acessados em espaços virtuais, tais como: Biblioteca Nacional, Biblioteca do Senado Federal e Center for Research Libraries. 


\section{F HEM Gutrathá}

ISSN: 1984-6444 | http://dx.doi.org/10.5902/1984644435456

Como aporte teórico, utilizou-se das discussões de Habermas (2000) sobre o desenvolvimento do pensamento na modernidade, a fim de constituir explicações capazes de demonstrar como o ensino na primeira metade do século XIX era projetado mediante uma regulamentação organizada pelo Estado e assimilada pela sociedade, com apoio do poder provincial.

Além da parte introdutória, das conclusões e referências, o texto abriga três seções: analisa o discurso da modernidade e a interferência dessa racionalidade na formação do Estado Imperial; discute a instrução primária como meio do agir comunicativo estatal; e também aborda algumas iniciativas de mobilização social, visando garantir o direito à educação, na Província do Pará.

\section{O discurso da modernidade e a formação do Estado Imperial}

Desde o período colonial até o final do século XIX, a educação brasileira passou por reformulações a fim de constituir uma estrutura que chegasse a corresponder ao que seria o ensino e ao que deveria ser ensinado através de programas pensados para cada época, por isso as práticas escolares correspondiam às demandas que o sistema em vigência lhes impunha como sendo oficial (RIBEIRO, 1993; MONTALVÃO, 2011; MARTINS, 2009).

Alguns exemplos dos marcos históricos dessa estruturação, podem ser encontrados na educação jesuítica e na de outras ordens religiosas que atuavam no setor nesse período, que, como definem Vidal e Hilsdorf (2001, p. 13), era sistematizada e ordenada pelo Ratio Studiorum. A partir de 1759, com a expulsão dos padres da Companhia de Jesus dos territórios da Coroa Portuguesa, o Marquês de Pombal redimensionou o ensino no espaço colonial brasileiro, criando as Aulas Régias, que, segundo Costa, Ananias e Araújo (2014, p. 254), correspondiam a uma educação pautada nas concepções pedagógicas voltadas para o estudo das humanidades, pertencente ao Estado Português e com a dotação de recursos públicos próprios.

Outro momento importante que podemos destacar é encontrado na Constituição do Império do Brasil, de 1824, como a primeira Lei que direcionou o 


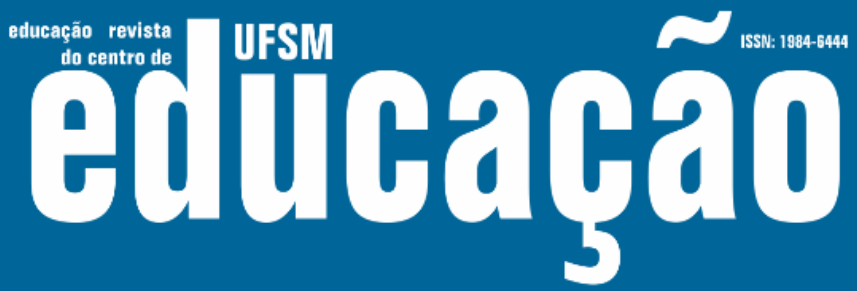

ISSN: 1984-6444 | http://dx.doi.org/10.5902/1984644435456

ensino a uma vertente mais popular e liberal por sua gratuidade (BRASIL, 1824, art. 179, XXXII).

Assim, o processo educacional do país foi produzido sob influências de concepções atreladas ao poder que definia o sentido da educação com base em postulados pedagógicos (SAVIANI, 2008), os quais contribuíam com a disseminação de um sentido de educação secularizada e, gradativamente, passou a ser tratada como princípio para a formação da população letrada.

A legislação educacional foi produzida, adaptada aos discursos que apregoavam a elevação do padrão de vida social em concomitância com a evolução do Estado rumo à modernidade, produzindo diretrizes para o funcionamento das instituições escolares, a realização do trabalho docente, o financiamento educacional, o currículo das disciplinas e tantas outras atividades referentes ao sistema de ensino, formuladas por meio das políticas reformistas com intenção de progresso.

No Brasil imperial, a tônica do discurso político nascente, caminhava para uma racionalização nas relações estabelecidas entre Estado e sociedade. Os textos legislativos, além de assegurarem a autoridade estatal, sugeriam uma relação de impessoalidade no tratamento para com o cidadão. A literatura legislativa incorpora aspectos do direito naquilo que determinava o dever do funcionário público, no desempenho de sua função, e também buscava afirmar a soberania do Estado perante as situações controversas que viessem a ocorrer, seja no campo político, econômico e segurança, quanto em possíveis crises no governo (NOGUEIRA: 2012, p. 10).

O Estado, na segunda metade do século XIX, configurou seu funcionamento tomando para si a responsabilidade da administração pública e passou a determinar as atividades dos órgãos e de seus agentes, adotando a postura da laicidade. A partir dessa intervenção, cada vez mais demonstrava sua ligação com as ideias das teorias empiristas e de suas derivações como o positivismo e o iluminismo, com suas influências no pensamento brasileiro, conforme análise de Salomão (2016) e Vasconcelos (2008).

Orientado pelas teorias engendradas no interior da modernidade, o Império brasileiro seguiu uma tendência que o conduziu pela prática administrativa calcada na 


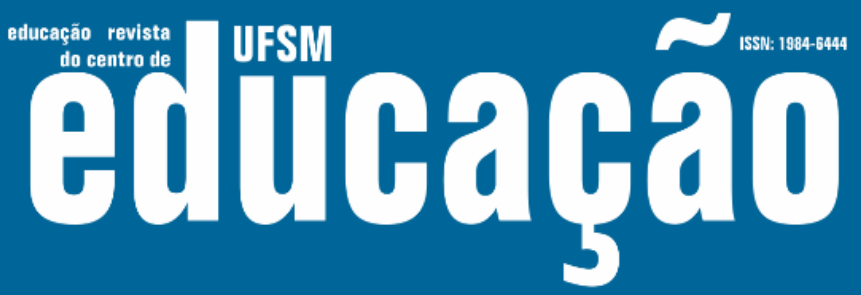

ISSN: 1984-6444 | http://dx.doi.org/10.5902/1984644435456

racionalidade das relações que começava a dar sentido às dinâmicas sociais entre Estado e cidadão, determinando a hegemonia do primeiro sobre os segmentos do sistema social, atividade que Santos (2013, p. 272) diz surgir com a concepção de Estado como unidade política, conceito este desenvolvido desde o século XVII.

Neste estudo, tem-se como referência de modernidade a concepção apresentada por Habermas (2000, p. 9), situando o contexto histórico engendrado pelos acontecimentos da descoberta do novo mundo, o Renascimento e a Reforma Protestante, o que demarca o fim do período medieval, trazendo consigo novas concepções teóricas sobre a presença do sujeito no mundo e sua relação com a natureza. Nesse sentido, os aportes epistêmicos desse movimento iniciado no século $X V I$, diferenciam do movimento do século XVIII que Hegel distingue chamando de "tempo mais recente", o qual traz consigo outros conceitos, como os de: Igualdade, Liberdade e Fraternidade, os quais, no Brasil, foram utilizados como bandeira de luta para o movimento republicano.

Nos registros da Colleção das decisões do Governo do Império do Brasil, acervo de documentos que reúnem atos dos poderes Executivo e Legislativo desde os anos 1808 a 1889², são apresentados todos os atos instituídos pelos dois poderes. Nesses documentos é possível observar o que Habemas (2000) define como discurso da modernidade, em que a moral religiosa edificadora da unidade passa a ser delegada à figura do Estado soberano, o qual se manifesta por meio de uma linguagem formal, geralmente respaldada em leis.

Habermas (2000) ao analisar a concepção weberiana da formação da modernidade no Ocidente, identificou-a como uma profanação da cultura causada por uma racionalidade, a qual formou esferas culturais de valor que possibilitaram ao sujeito social assimilar concepções de "problemas teóricos, estéticos ou práticosmorais, segundo suas respetivas legalidades internas" (HABERMAS, 2000, p. 4), que estão ligadas aos sistemas dos núcleos organizadores da empresa capitalista e ao aparelho burocrático do Estado, que reincidem dissolvendo as formas de vida tradicionais.

É entendendo a tônica do envolvimento que o Estado imperial brasileiro teve com as forças produtoras da modernidade, que podemos perceber a assimilação dos 


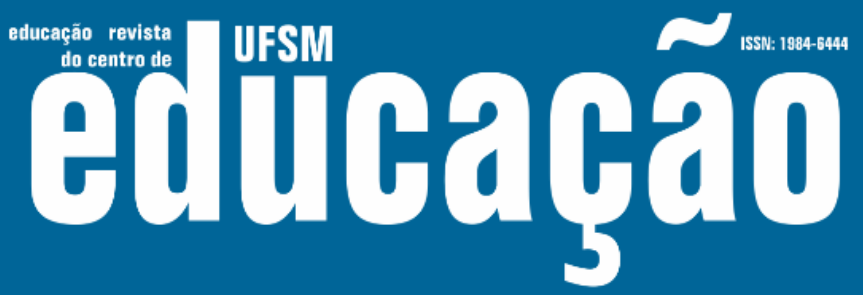

ISSN: 1984-6444 | http://dx.doi.org/10.5902/1984644435456

valores teóricos dessa concepção, como, no caso, a partir da organização da política econômica que deixa de ser baseada no mercantilismo e começa a ser estribada sob a orientação do negócio envolvido com uma pequena burguesia urbana que estrutura o comércio com base no mercado influenciado pelas tendências do capitalismo, que, no caso da Província do Grão-Pará, voltava-se ao extrativismo da borracha e a interiorização do território, conforme analisou Tavares (2008, p. 65-66).

Junto a este, há outros fatores, como os apontados por Machado (1980, p. 128), que diz ser nesse regime que a sociedade é subordinada ao Estado definido como patrimonialista, no qual são exacerbadas as influências políticas, uma vez que se constitui o contexto da presença de relações interpessoais entre classes e grupos, em que a cultura da elite se alimentava do pensamento universal europeu.

Embora no século XIX o Brasil tivesse uma população essencialmente rural, cuja economia girava em torno da agricultura e do extrativismo, a escravidão ainda era presente e o aspecto religioso continuava determinando as regras do comportamento moral. Assim, a escravidão marcou a formação da sociedade brasileira desse período, portanto, dava lucros e o Brasil se fez com a escravidão (GORENDER, 2002).

O sistema social do século XIX deixava transparecer, nas relações sociais e nas atividades, que os sujeitos participantes dessa estrutura, como o Estado e os cidadãos, realizam os elementos que Habermas (1997, p. 95) diz caracterizar a modernidade, geradora de mudanças nas formas de vidas tradicionais, empregando o discurso prático no uso moral da razão, na criação de normas e leis de conduta, com peso epistêmico para a vida em sociedade, atividade que se caracteriza pela construção de uma fala comum naquele tempo histórico que vivenciaram.

$\mathrm{Na}$ concepção habermasiana (2000, p. 125.), no contexto da modernidade, o Estado é um ente soberano com espaço territorial delimitado que abriga uma sociedade circunscrita a seu território. A essa concepção está atrelada a ideia de nação como significado de uma "comunidade política marcada por ascendência comum" por sua língua, cultura e história. Daí decorre que o sistema social brasileiro do século XIX, quando se estrutura o período imperial, começa a assumir essa identidade, desenvolvendo políticas que caminham na direção de determinar o ente 


\section{Autuaŗão}

ISSN: 1984-6444 | http://dx.doi.org/10.5902/1984644435456

estatal enquanto soberano. Exemplo dessa atuação sistemática do Estado pode ser notado abaixo:

A Regencia Permanente em Nome do Imperador o Senhor Dom Pedro II Há por bem Sanccionar e Mandar que se execute a seguinte Resolução da Assembléa Geral Legislativa.

Art. 1.ㅇ O Governo fica autorizado a prover de professores ideoneos as cadeiras de philosofphia, geometria e francez para a capital da Provincia de Goyaz, pela primeira vez, precedendo os exames necessários (BRASIL, 1834, p. 2).

Em razão desse dispositivo legal, o Imperador, como responsável pelo Estado, determinava ações em vista de atender a demanda social da circunscrição do território, utilizando nesse ensejo o emprego de medidas que também incidiam na construção de valores morais. Nesse sentido, vale reafirmar a presença dos elementos que caracterizam a modernidade, não somente como um movimento de oposição ao pensamento medieval ou escolástico, mas também enquanto tendência fundada em concepções teóricas que preveem a atuação do Estado absolutista, o qual determina as normas de conduta em todos os setores, inclusive para o funcionamento da educação.

Seguindo a tendência de Estado soberano, naquela conjuntura as províncias do país também se orientavam para organizar a gestão, buscando atender a todos os setores da administração pública imperial com base em ideias da teoria prática, causadoras de muitos embates, à época, segundo consta do estudo desenvolvido por Malheiros e Santos Filho (2014) a respeito da criação da Escola Normal no Grão-Pará.

Nesse caso, para demonstrar a ideia de supremacia do Estado, tem-se como exemplo a mensagem do Governador Provincial do Pará, Bernardo de Souza Franco, que, tratando da matéria "Tranquilidade Pública", relata as medidas tomadas referentes às insurgências que estavam ocorrendo em algumas vilas e cidades da província:

E deixando as formulas exteriores, notai, Senhores, que conservando eu todos esses meios de força, que tão necessários são em Paiz, apenas sabido do vórtice da anarchia, e que qualquer imprudência pôde ainda perder irremediavelmente, nenhuma abuzo tenho delies feito, e tudo volta a seu estado normal insensivelmente. Cessarão as violências, vai desaparecendo o constrangimento, a Agricultura e Commercio se reanimarão, sem reformas, [...] Conservai, Senhores, na parte que vos toca, toda a força ao Governo, e convencida como está a população toda de que a mais severa economia reina na despeza dos dinheiros públicos de que as primeiras Authoridades 


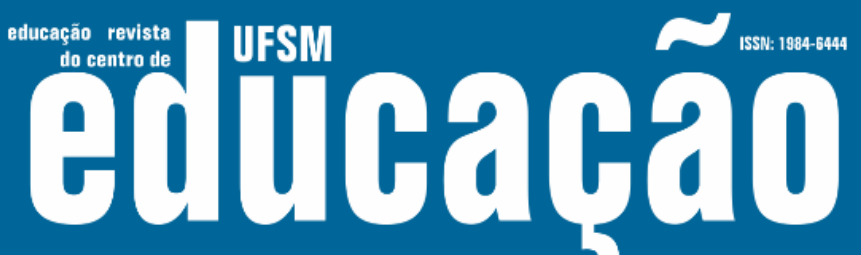

ISSN: 1984-6444 | http://dx.doi.org/10.5902/1984644435456

exemplo de desinteresse e zelo pelo bem público e que estão determinadas a dar aos bons toda a proteção e fazer guerra de morte aos rebeldes tenazes, e a Provincia virá a completa ordem [...] (PARÁ; 1839, p. 3).

Após o relato das medias empregadas, a mensagem do Presidente da Província adquire o tom de imposição do poder, demonstrando a força do Estado em defesa própria, indicando quais setores beneficiados com sua ação enérgica, sugerindo, assim, que ele está presente em todos os contextos sociais, preocupado com o bom andamento da coisa pública e a tranquilidade da sociedade. Dessa forma, o discurso presidencial provinciano, acompanha as premissas da teoria da administração pública do Estado que o paradigma teórico ideológico do período sugere para o período histórico.

Com isso, evidencia-se que no período imperial, o Estado Brasileiro está entrelaçado ao movimento da modernidade, assumindo postura deliberativa com relação ao atendimento das demandas da sociedade, pautando suas ações com base em normatizações regimentais e que os cidadãos são submetidos ao contato, de modo a e se inteirar da formalidade para a utilização desse instrumento como meio de viabilizar a garantia de alguns direitos sociais. Assim, nota-se a constituição de um campo por meio da fala comunicacional em que Estado e sociedade se relacionam, compondo o contexto histórico que vivenciam.

\section{Instrução primária como meio do agir comunicativo estatal}

No decorrer da história da colonização do Brasil, as divisões territoriais em províncias foi uma política adotada pela Coroa Portuguesa e mantida durante a formação do Império, respeitando as influências oligárquicas de famílias tradicionais, como indica Dallari (2000), ao discutir a separação de poderes a partir da formação do quadro legislativo bicameral, como uma espécie de democracia representativa, com a concentração do poder na pessoa do Imperador.

A Província do Pará esteve intimamente ligada às atividades econômicas e políticas coloniais, posto seu território ser de grande importância estratégica para a movimentação do mercado, devido à imensa quantidade de riquezas extrativistas à época, dentre as quais se destacava o comércio da borracha, que foi o centro da 


\section{T usm Allthapã}

ISSN: 1984-6444 | http://dx.doi.org/10.5902/1984644435456

atividade econômica e do enriquecimento de muitas famílias europeias que se instalaram na região.

Devido ao fator econômico que girava em torno do mercado da borracha e de outras matérias-primas também de grande valor no comercio internacional, as porções de terras de mais fácil acesso por via marítima foram sendo loteadas no sistema de concessão de posse da sesmaria. Assim, as primeiras localidades a serem povoadas pelas famílias colonizadoras estavam próximas à capital da Província, Belém, e deram origem às vilas que, mais tarde, tornaram-se cidades como Moju, Barcarena, Acará, Abaetetuba, Igarapé-Miri, Bujaru e Cametá, o que corresponde atualmente à região conhecida como Baixo Tocantins. O Pará, ao longo da história brasileira, passou por diversas transformações de seu espaço territorial (TAVARES, 2008).

O processo de disseminação da educação, que começou a ser desenvolvido nesse período através das ordens religiosas, vem sendo entendido como um dos mecanismos acionados para a manutenção da política colonial, como indica a descrição seguinte:

A primeira phase da instrucção publica do Pará, contada do primitivo aldeiamento pertuguez aos decretos pombalins contra os frades, pertenceu exclusivamente á influencia religiosa.

Fundada Belém em 1616, contava, dez annos depois, dois conventos, um de caremelitas, e outro de capuchos de Santo Antonio; nestas casas religiosas exerciam os frades o magistério.

Os mercenairos (mercedários) em 1640; os jesuítas em 1653; os religiosos de Beira e Minho, em 1706; os religiosos da Piedade em 1749; [...] os frades tornaram-se as únicas fontes de instrucção na capital e no interior (VIANNA, 1987, p. 4).

Destaque-se que mesmo em meados do século XVIII, no Estado do Grão-Pará e Maranhão, houve iniciativas no intuito de organizar as escolas estatais, por meio das reformas educacionais consubstanciadas no Diretório dos Índios de 1757, aprimorando-se o projeto colonial e promovendo a civilização dos índios (DAMASCENO, 2012, p. 156-181).

A introdução do processo educacional iniciado na colonização, de acordo com Costa e Corrêa (2010, p. 2), representou um instrumento fundamental para que, no período posterior, o ensino primário fosse fixado na Província através da criação de escolas primárias, liceu, ginásio e academias, e que teve seu desdobramento através 


\section{$\sim 7$ Eutoabुa}

ISSN: 1984-6444 | http://dx.doi.org/10.5902/1984644435456

da lei de 15 de outubro de 1827, a qual obrigava a criação do ensino primário nas cidades e vilas mais povoadas ${ }^{3}$.

Fruto da atuação do Imperador Pedro I, essa lei que "Manda crear escolas de primeiras letras em todas as cidades, villas e logares mais populosos do Imperio", determinava:

Dom Pedro, por Graça de Deus, e unanime acclamação dos povos, Imperador Constitucional, e Defensor Perpetuo do Brazil: Fazemos saber a todos os nossos subditos, que a Assembléa Geral decretou, e nós queremos a lei seguinte:

Art 1 $\mathrm{Em}$ todas as cidades, villas e logares mais populosos, haverão as escolas de primeiras letras que forem necessarias.

Art $2^{\circ}$ Os Presidentes das provincias, em Conselho e com audiencia das respectivas Camaras, emquanto não tiverem exercicio os Conselhos geraes, maracarão o numero e localidades das escolas, podendo extinguir as que existem em logares pouco populosos e remover os Professores dellas para as que se crearem, onde mais aproveitem, dando conta á Assembléa Geral para final resolução.

Art 3ํㅡㄴ Os Presidentes, em Conselho, taxarão inteiramente os ordenados dos Professores, regulando-os de $200 \$ 000$ a $500 \$ 000$ annuaes: com attenção ás circumstancias da população e carestia dos logares, e o farão presente á Assembléa Geral para a approvação.

Art 4ํㅡㄹ As escolas serão de ensino mutuo nas capitaes das provincias; e o serão tambem nas cidades, villas e logares populosos dellas, em que fór possivel estabelecerem-se.

Art 5ำ Para as escolas do ensino mutuo se applicarão os edifficios, que houverem com sufficiencia nos logares dellas, arranjando-se com os utensillios necessarios á custa da Fazenda Publica e os Professores; que não tiverem a necessaria instrucção deste ensino, irão instruir-se em curto prazo e á custa dos seus ordenados nas escolas das capitaes (BRASIL, 1827).

Esse ensino contava com uma estrutura de instituições criadas com a finalidade de levar à população a instrução sistematizada no ensino das disciplinas escolares e no trabalho de professores e outros profissionais que atuavam em favor da manutenção do ensino, como os delegados da instrução pública, que fiscalizavam o andamento do trabalho docente e o funcionamento das aluas primárias, sobretudo no interior da província.

A lei de 1827, além de prever a criação constitucional das escolas de primeiras letras, também estabelecia atribuições a serem cumpridas pelos professores:

Art 60 Os Professores ensinarão a ler, escrever as quatro operações de arithmetica, pratica de quebrados, decimaes e proporções, as nações mais geraes de geometria pratica, a grammatica da lingua nacional, e os principios de moral chritã e da doutrina da religião catholica e apostolica romana, proporcionandos á comprehensão dos meninos; preferindo para as leituras a Cosntituição do Imperio e a Historia do Brazil. 


\section{N Eulloabुa}

ISSN: 1984-6444 | http://dx.doi.org/10.5902/1984644435456

Art $7^{\circ}$ Os que pretenderem ser providos nas cadeiras serão examinados publicamente perante os Presidentes, em Conselho; e estes proverão o que fôr julgado mais digno e darão parte ao Governo para sua legal nomeação. Art $8^{\circ}$ Só serão admittidos á opposição e examinados os cidadãos brazileiros que estiverem no gozo de seus direitos civis e politicos, sem nota na regularidade de sua conducta.

Art 9o Os Professores actuaes não seram providos nas cadeiras que novamente se crearem, sem exame e approvação, na fórma do art. $7^{\circ}$.

Art $10^{\circ}$ Os Presidentes, em Conselho, ficam autorizados a conceder uma gratificação annual, que não exceda á terça parte do ordenado, áquelles Professores, que por mais de doze annos de exercicio não interropindo se tiverem distinguindo por sua prudencia, desvelos, grande numero e approveitamento de discipulos (BRASIL, 1827).

O desenvolvimento do ensino na Província do Pará, ao longo do processo de colonização e depois, durante o período imperial, seguiu uma ordem progressiva, voltado à expansão da instrução e elevação dos padrões de vida da população, aplicando métodos de organização e trabalho ao projeto educacional de uma sociedade que, paulatinamente, identificava-se com parte de uma nação e com isso assimilava as ideias enredadas na lógica da racionalidade do padrão de homem moderno prenunciado pelas relações estabelecidas no meio social.

No decorrer do período imperial, na Província do Grão-Pará, transcorreram debates em torno da necessidade de se criar ou não a Escola Normal, entre os anos de 1838-1871 (MALHEIROS; SANTOS FILHO, 2014); o surgimento do Liceu Paraense, em 1841 (GASPAR; BORGES; CHAQUIAM, 2010); iniciativas no âmbito da educação feminina, mediante criação, no ano de 1851, do Colégio Nossa Senhora do Amparo (SOUSA, 2014); ações estatais no âmbito da formação de professores (FRANÇA, 2012); medidas visando promover a organização da instrução pública primária (FRANÇA; NERY, 2016); assim como a criação da Escola Rural Pedro II, para formar trabalhadores, operários, feitores e administradores de estabelecimentos rurais (NUNES, 2014).

Essas diferentes formas de intervenções, evidenciam a forte presença do Estado no setor da educação, no período Imperial, seja legislando sobre a criação de instituições educativas, ou definindo padrões de organização do ensino e da regulamentando do trabalho docente. 


\section{T usm Eulloabato}

ISSN: 1984-6444 | http://dx.doi.org/10.5902/1984644435456

\section{Mobilização social visando garantir o direito à educação na Província do Pará}

O Estado imperial, para manter sua hegemonia sobre a sociedade, utilizou-se dos dispositivos do direito fundados na legalidade, por isso as leis criadas são uma forma de expressar a legitimidade do Império em impor sobre a sociedade sua regência para dirigir as províncias e a vida dos cidadãos. Esse tipo de direito Habermas, (2012, p. 453) caracteriza como "moderno positivo estatuído", que expressa a vontade de um legislador soberano, o qual regulamenta a situação social subsistente.

O discurso empreendido dá a noção da conjuntura formada no âmbito do totalitarismo que revela o papel da autoridade do Imperador e, por conseguinte, do Estado que não deixa espaço para a manifestação da sociedade, por impor seus desígnios, valendo-se da ideia da consumação do poder como determinado, seja por princípios religiosos, ou convencionais, firmado através do direito legalizado.

Nessa perspectiva, Silva (1997), ao se referir ao início do Estado de Direito brasileiro, reporta sua experiência à legislação lusitana, adquirindo características peculiares, dentre as quais se destaca a racionalidade:

[...] O direito moderno formaliza as relações sociais segundo normas jurídicas. Não é mais o conteúdo da ação de um agente social que impulsiona outra ação e sim a forma pela qual o agente social incorpora o sentido da ação como regra orientadora de sua conduta na sociedade (SILVA, 1997, p. 67-68).

A formalização do direito pelas normas jurídicas, tornou-se uma maneira de o Estado manter sua soberania. Entretanto, embora as leis sejam totalitárias em um regime absolutista, deixam margens para a ação popular. E foi valendo-se dessa possibilidade oportunizada pela legislação que na então vila de $\mathrm{Moju}^{4}$, território da Província do Pará, iniciou o ensino primário como noticiado no Jornal do Comércio do dia 23 de novembro de 1840: "O parocho e o comandante militar de Mojú pedem a creação de huma escola de primeiras letras" (JORNAL DO COMÉRCIO, 1840, p.2).

Conforme noticiado no Jornal do Comércio, foi a partir da mobilização popular, da união de forças de duas representações da sociedade, que chegou até aos altos 


\section{U Lism Althapa}

ISSN: 1984-6444 | http://dx.doi.org/10.5902/1984644435456

escalões estatais a demanda por educação na vila de Moju, no interior da Província do Pará, que pelo Decreto nำ111 de 25 de setembro de 1843, criou a "cadeira do ensino primário nas freguesias do Acará e Mojú (PARÁ, 1843)". O que significa dizer que, serviços como a educação, no movimento da modernidade, são discursos que fazem parte do diálogo da sociedade, que começa a entender a política como campo de relações em que estão envolvidas as representações superiores do ordenamento jurídico e político estatal.

José Thomaz Henriques, Oficial das Ordens Imperiais do Cruzeiro e Rosa, Cavaleiro das de Cristo e S. Bento d'Aviz, Coronel da Infantaria de Linha do Estado Maior de 1 a Classe, e Presidente da Província do Grão Pará \&.

Faço saber a todos os seus habitantes, que a Assembléia Legislativa Provincial resolveu e eu sancionei o seguinte Decreto.

Art. Único. Fica aprovada a criação das cadeiras de ensino primário nas freguesias do Acará e do Mojú.

Ficam revogadas todas as Leis e disposições em contrário.

Mando, portanto, a todas as Autoridades a quem o conhecimento deste Decreto pertencer, que o cumpram, e façam cumprir tão inteiramente como nele se contém. O Secretário desta Província o faça imprimir, publicar e correr. Dado no Palácio do Governo do Pará aos vinte e cinco dias do mês de setembro de mil oitocentos e quarenta e três, vigésimo segundo da Independência e do Império.

L. S.

José Thomaz Henriques.

Francisco Carlos Mariano o fez.

Selado e publicado na Secretaria do Governo em 26 de setembro de 1843.

O Secretário, Miguel Antonio Nobre.

Registrada a folha 108 do Livro 1. de Leis, Decretos e Resoluções Provinciais. Secretaria do Governo do Pará, 30 de setembro de 1843. João José Pereira.

Observa-se que somente dezesseis anos após a entrada em vigor da lei de criação das Escolas de Primeiras Letras, em 1827, passou-se a proclamar o direito ao ensino primário, mediante ato decretado em 1843 pelo então Presidente da Província do Pará (José Thomaz Henriques). Contudo, essa situação não foi revertida, tanto que no ano de 1851 o Presidente da Província do Pará (Fausto Augusto D’Aguiar), produziu nova lei para tentar organizar o funcionamento das escolas primárias.

No processo de evolução da sociedade brasileira no período imperial, a educação foi ambiente de relação social, posto ser através do desempenho da institucionalização do ensino primário, da construção de prédios escolares, do investimento de recursos financeiros que as partes da sociedade se encontravam para 


\section{工 Wism Eutoraba}

ISSN: 1984-6444 | http://dx.doi.org/10.5902/1984644435456

dialogar, e aos poucos com esse contato a camada mais popular foi aprendendo a fazer uso dos ritos oficiais para adquirir e negociar vantagens, como, por exemplo, a mudança no modo de atendimento do ensino primário na vila de Moju, como consta no Jornal "A Epocha"5 (1859a):

\section{DESPACHOS}

Dito - Do padre Angelo Custodio de Sousa, professor interino da cadeira do ensino primário do $1^{\circ}$ gráo da villa do Mojú, pedindo que seja elevada a dita cadeira a $2^{\circ}$ gráo na conformidade da lei provincial $n^{\circ}-293$ de 27 de outubro de 1851, por estar sendo actualmente frequentada pelo número de 86 alunos. Foi a informar, ao director da instrucçaõ publica (A EPOCHA, 1859a, № 12 p. 1).

Dadas as condições da época e da posição geográfica do município de Moju, situado no extremo norte da região amazônica, a viabilidade de serviços públicos se tornava quase impossível, muito embora, no período colonial e imperial, essa localidade tivesse relevância pela possibilidade de navegação fluir por seu rio. Mesmo assim, as atividades do Estado no lugar eram incipientes, e foi nesse cenário que o professor do ensino primário utilizou o texto da lei para conseguir vantagens e assegurar a classificação da turma do primeiro grau do ensino primário para segundo grau do mesmo nível de ensino. A lei a que o texto se refere está em Pará (1851), determinando que:

Artigo $2^{\circ}$. O presidente da província estabelecerá as escolas do $1^{\circ}$ grau da instrução primária em todas as localidades da Província, em que possam reunir-se de 15 a 30 meninos; e as do $2^{\circ}$ grau naquelas que possam concorrer de 30 a 100; nas localidades onde este máximo for excedido, poderá o Governo criar novas escolas do 2ograu (PARÁ, 1851).

A lei $203 / 1851^{6}$, que disciplina o funcionamento das escolas primárias, foi a maneira técnica, pautada no quantitativo de matrículas, que o Estado encontrou para fazer a divisão entre vilas e cidades que tinham condições de ofertar um ensino mais aprofundado, das vilas e cidades que poderiam ter apenas os conteúdos básicos, como está expresso em Pará (1859):

A lei $n^{0} 203$ de 1851 estabeleceo esta regra: = A escola que tiver menos de 30 alumnos será de 1 o gráo: a que tiver mais de 30 será de $2^{0}$ gráo.

Como condição inherente ás escolas de $2^{\circ}$ gráo, estabeleceo a mesma lei que n'elas se insinaria o dobro das matérias admitidas nas do $1^{\circ}$ gráo.

A base legal da classificação é, portanto, a maior ou menor somma de alunos, tomando-se o no 30 como linha divisoria; e a condição é o ensino de 5 materias nas escolas de $1^{\circ}$ gráo, e de 10 nas de $2^{\circ}$ (PARÁ, 1859, p. 33). 


\section{F WFH Ellloahă}

ISSN: 1984-6444 | http://dx.doi.org/10.5902/1984644435456

Para além de uma ciência administrativa e da ação legislativa do período imperial, e que somente alguns tinham acesso, devido ao pouco número de pessoas com formação nessa área, as camadas populares conseguiam desenvolver formas de acessar as políticas oficiais do Estado. Com relação à melhoria na qualidade de ensino na vila de Moju, a estratégia adotada foi garantir a quantidade de matrículas necessárias para mudança de estrutura de ensino. E sendo que o professor do ensino primário era o vigário do vilarejo, seu contato com os moradores facilitava a mediação com a sociedade.

Optando pela classificação de segundo grau do ensino primário, a instituição escolar da vila de Moju teria que dispor de recursos materiais mínimos, como carteiras, lousa e sala ampla para comportar um número grande de alunos. E mesmo que em Moju o ensino primário tenha sido instituído em 1843, nesse período não há registro de prédio escolar na localidade, o que leva a inferir que o Padre Angelo Custódio tenha se servido do espaço da igreja para realizar as atividades de ensino da escola.

A alteração na forma de organização e funcionamento do ensino no nível primário, de classe de primeiro grau para classe de segundo grau, também ocasionou uma outra alteração nessa modalidade, que deixou de ser individual para mútuo. Nesse sentido, é possível observar que o Estado Imperial, pela praticidade, incorpora sistemas teóricos que são mais eficientes às necessidades da realidade, e no caso da educação, o sistema lancasteriano ${ }^{7}$ era o visado por reunir em uma mesma sala alunos com idades e níveis diferentes, como ressaltam Stephanou e Bastos (2012, p. 72), técnica que para a época pode ser considerada uma novidade, tanto para o trabalho docente no que diz respeito à gestão do espaço, tempo e conteúdo, quanto para os alunos, que teriam de se adaptar a essa configuração.

A propósito, as disciplinas a serem estudadas no primeiro grau eram: 1. Leitura e escrita, 2. Aritmética e proporções, 3. Gramática e ortografia prática, 4. Noções e deveres morais e religiosos e 5. Doutrina Cristã. Para o ensino na classificação de segundo grau, o ensino compreendia: 1. Leitura e escrita, 2. Aritmética e proporções, 3. Dita com aplicação ao comércio, 4. Geometria prática, 5. Gramática e Ortografia portuguesa, 6. Noções gerais de geografia do Império, 7. Ditas gerais da História do 


\section{T usm Euttagha}

ISSN: 1984-6444 | http://dx.doi.org/10.5902/1984644435456

Brasil, 8. Ditas gerais dos deveres morais e religiosos, 9. Doutrina Cristã e 10. Leitura da constituição e do Código Penal do Império.

O que chama a atenção, além da quantidade de cadeiras para um só professor assumir, é a diversidade de áreas de conhecimento, situação que também preocupava o Presidente da Província do Pará, que acreditava ser um equívoco o fato de a troca de classificação de primeiro para segundo grau se dar de acordo com o quantitativo, pois isso traria implicações para o status da habilitação do professor, que teria aumentado o número de disciplinas a ministrar.

Uma questão em evidência nisso tudo é o fato de o professor, que é um sujeito social, membro de uma comunidade do interior da Província, mobilizar-se para a mudança na classificação da turma do ensino primário, ação que leva à compreensão de que a sociedade foi persuadida pelo poder estatal e estava interessada no processo de disseminação da instrução pública.

Embora essa fosse uma ação governamental, a própria sociedade estava envolvida nessa contenda por perceber a possibilidade da obtenção de vantagens através do sistema de ensino, e para isso utilizava os dispositivos legais visando melhorias a seu atendimento. Desse modo, em 06 de junho de 1859, foi noticiado pelo jornal A Epocha o despacho favorável à classificação de segundo grau o ensino primário de Moju.

As resoluções normativas do período imperial eram redigidas com base no princípio do direito, o que dava à sociedade a expectativa de poder buscar, através da legalidade, meios para garantir o que estava determinado na lei. Desse modo, igual à ação movida pelo professor do ensino primário de Moju, também a professora Antônia de Jesus Gomes Franco, solicitou sua admissão para a cadeira do ensino primário feminino na mesma vila, conforme está noticiado no Jornal A Epocha (1859b):

\footnotetext{
- De Antonia de Jesus Gomes Franco ex-educanda do collegio de N. S. do Amparo, pedindo ser admitida ao exame que se tem de proceder para provimento da cadeira de ensino primário do sexo feminino ultimamente creada na villa de Mojú.

Idem (despachado) ao director da instrucçaõ publica (A EPOCHA,1859b, no 48, p. 2).
} 


\section{Autuaŗão}

ISSN: 1984-6444 | http://dx.doi.org/10.5902/1984644435456

O pedido de admissão da professora Antônia, por meio de concurso, constituiu uma ação individual, entretanto, esse procedimento demonstrava que novamente os sujeitos sociais se conectavam aos procedimentos legais para adquirir seus direitos. Nota-se que o dispositivo legal é novamente acionado, pois, se a professora entrou com o pedido de admissão ao exame, foi devido a dois fatores: o primeiro, resultou do fato de em Moju haver o quantitativo de alunas suficiente para a realização do ensino primário feminino; e o segundo, em razão de a professora ter habilitação adequada adquirida no Colégio Nossa Senhora do Amparo, requisitos suficientes para credenciá-la a assumir referida cadeira. Essa instituição, também denominada Recolhimento das Educandas, foi criada em 1804, direcionada ao sexo feminino e funcionava em regime de internato (VASCONCELOS; OLIVEIRA; COSTA, (1992).

As ações movidas pela via jurídica envolvendo a legislação, converteram-se em recurso essencial na ação comunicativa no contexto da modernidade, e isto trouxe para a sociedade mecanismos reguladores por meio dos quais colocou no cenário das relações políticas, as possibilidades de usufruto do direito, particularmente no que se refere ao campo educacional.

O Estado imperial brasileiro, e nele a Província do Pará, colocava-se como elo aos interesses advindos da sociedade fragmentada em Vilas, Cidades, Capitais, particularmente dos atores sociais que se ocupavam do ofício de professores nas Escolas de Primeiras Letras, e almejavam melhorias na organização e funcionamento dessas instituições educativas.

França e Nery (2016), estudaram a "organização da instrução pública primária na província do Pará no período de 1851 a 1861", evidenciando que as Escolas Primárias não eram disponibilizadas na proporção do que demandava a sociedade da época, mas cumpriam com seu papel político:

Nota-se que a Lei o 203 de 27 de outubro de 1851 explicitava o anseio do governo em associar a leitura nas escolas aos elementos ideológicos do catolicismo e dos preceitos do Império. Essa determinação evidenciava que a preferência por conteúdos doutrinários (religiosos e políticos) imbuídos nos textos escolares da instrução primária, tinha como finalidade a moralização do nascente cidadão da província do Pará, onde excluía o indígena e o escravo (FRANÇA; NERY, 2016, p. 401). 


\section{Autตaดูão}

ISSN: 1984-6444 | http://dx.doi.org/10.5902/1984644435456

Dentre os diversos interlocutores, os atores religiosos e políticos representam os sujeitos privilegiados atuantes dentro da estrutura funcional do Estado Imperial. Disto resultam mediações em torno de distintos interesses, tais como: expansão das Escolas Primárias para vilas e lugares mais populosos; e a alocação da mão de obra do Professor para o exercício do trabalho docente nessas instituições; ocupação do cargo de diretor de ensino. Assim, a intervenção estatal, por meio de seus regulamentos, almejava o controle cívico e moral do ensino, a fim de escolarizar o cidadão para servir ao Império.

Apesar dessa medida legal, a situação do ensino primário na Província do Pará, não se apresentava em boas condições, ainda que a quantidade de escolas tenha sido ampliada, pois, havia professores inaptos atuando; a população estudantil atendida era baixa em relação ao contingente existente e estava concentrada no atendimento de meninos, sendo reduzida a incidência de meninas; falta de prioridade na criação de Escola Normal para formar professores; adoção do critério de afinidade política para recrutar professores; a baixa remuneração concedida aos professores o que dificultava a exigência de melhor desempenho por parte da administração; negligência e omissão dos pais em prover educação dos filhos; elevado índice de reprovação dos alunos; espaços (públicos e domésticos) precários para funcionamento das escolas (FRANÇA; NERY, 2016, p. 402-412).

Tanto na fase em que se constituía como Província do Pará, quanto na Primeira República, a presença de meninos e meninas desvalidos foi marcante no período de 1804 a 1912, o que demandou a interlocução do Estado com as organizações religiosas que atuavam com essa demanda, como também a iniciativa desse mesmo ente estatal, a partir da segunda metade do século XIX, na oferta de instituições próprias para absorver essa fração da população (SOUZA, 2010).

Oportuno destacar a manifestação dos conflitos de interesses em torno das instituições educativas, em particular no que se refere às Escolas Normais e projetos de Universidades no contexto imperial: 


\section{T usm Autbahat

ISSN: 1984-6444 | http://dx.doi.org/10.5902/1984644435456

É importante ter em mente que, após o Ato Adicional de 1834, a pauta das escolas normais, igualmente ao assunto das universidades, se tornou mais motivo de competições discursivas do que proposta de fato para qualificar os docentes do ensino de primeiras letras e ensino secundário na província (CARDOSO, 2016, p. 34).

Assim, a oferta, política de expansão, financiamento e o preparo adequado do professor para atuar no ensino primário ou secundário, mais se configurava como "competições discursivas" em torno da regulamentação e controle da vida organizada na sociedade, mantendo-se os privilégios da elite, do que efetivar propostas visando dotar da qualidade necessária a precária estrutura educacional existente.

Com a edição do Ato Adicional de 1834, houve revisão da Constituição de 1824, e por meio de seu art. $10, \S 2^{\circ}$ as Assembleias Legislativas Provinciais passaram a ser competentes para legislar "Sobre instrucção publica e estabelecimentos proprios a promovel-a, não comprehendendo as faculdades de Medicina, os Cursos Juridicos, Academias actualmente existentes e outros quaesquer estabelecimentos de instrucção que para o futuro forem creados por lei geral” (BRASIL, 1834).

Segundo Castanha (2006, p. 171) “O Ato Adicional foi o marco que desencadeou uma vasta discussão entre centralização e descentralização no Brasil imperial, principalmente no campo educacional". Além disso, estimulou intenso e controverso debate na produção historiográfica educacional, uma vez que muitos historiadores destacam os efeitos negativos decorrentes dessa medida reformista, outros, sobrelevam a autonomia das províncias na produção de suas leis e organização do ensino.

\section{Conclusões}

A modernidade introduziu na sociedade concepções teóricas que redefiniram o papel do sujeito. Desse modo, as instituições modificaram suas estruturas, incorporando em seu discurso os elementos desse novo tempo.

A partir dessa orientação epistemológica, o Estado se configurou sob a forma de um ente mantenedor da ordem social, para tanto fundamentando suas ações em leis que legitimavam a sua soberania, mas, ao optar pela legislação como mecanismo 


\section{Ej|lिa}

ISSN: 1984-6444 | http://dx.doi.org/10.5902/1984644435456

ordenador, possibilitou à sociedade o exercício do poder para se manifestar na busca de direitos.

$\mathrm{Na}$ Província do Pará, o ensino primário contava com uma estrutura bem definida no que se pretendia com seu funcionamento, a saber: a instrução pública era regulada por normatizações constituídas no âmbito da legislação; havia orientação de método para seu desenvolvimento; alusão à organização de recursos de gastos financeiros; existia política reguladora do quadro profissional do magistério, o que leva a visualizar um cenário de simplificado aparelhamento, mas com indícios de organização estrutural.

$\mathrm{Na}$ época do governo imperial na vila de Moju, as políticas desencadeadas na Província do Pará, não se efetivavam para o atendimento total da população. Nesse sentido, as ações dos cidadãos podem ser consideradas formas de interferir na estrutura do sistema que limitava a relação do Estado com a sociedade, e assim dinamizar a vida do lugar, abrindo mais oportunidades de melhorias àquela população. Desse modo, os sujeitos envolvidos na disseminação do ensino participavam dessa construção ao matricularem seus filhos nas aulas do ensino primário, ou através da força da lei, buscando a concretização do direito.

Por mais que no contexto histórico da Província do Pará os gestores públicos, na figura de seus Presidentes provinciais, tenham sido exitosos na criação de leis visando regulamentar a oferta do ensino primário nesse espaço territorial, os efeitos dessa atuação política se projetaram na ampliação das escolas para diversas localidades.

Permaneceu acintosa a precarização do trabalho realizado pelos professores, pois estes eram desprovidos de formação, recebiam baixa remuneração, assumiam diversas disciplinas do currículo, e não dispunham de espaços adequados para o exercício do trabalho pedagógico, consequentemente, a aprendizagem era comprometida e se expressava no elevado índice de reprovação escolar, colocando em risco a viabilidade do projeto ideológico moralizador da sociedade imperial no Brasil.

Além de instituir sua interferência na sociedade a partir das regras jurídicas, o Estado brasileiro e suas Províncias, na fase imperial, também faziam circular as 


\section{T Wsm \\ ISSN: 1984-6444

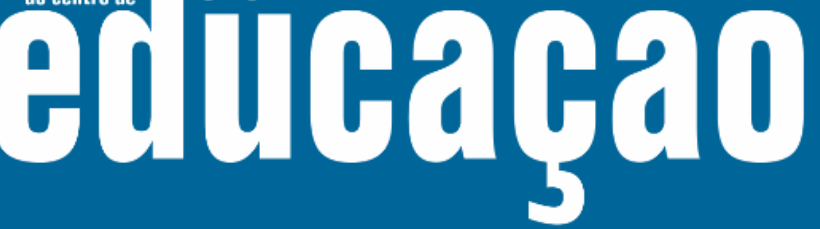

ISSN: 1984-6444 | http://dx.doi.org/10.5902/1984644435456

normas regulamentadoras por meio dos jornais, relatórios, a imprensa, na organização e funcionamento curricular, na seleção dos conhecimentos oficiais ensinados nas instituições escolares, e pela inspeção e controle sobre o trabalho dos professores, de modo a incluir o outro na teia discursiva baseada na racionalidade das ações públicas e da forma como se efetiva a distribuição dos papeis sociais, principalmente tendo a oferta do direito à educação e o acesso às Escolas de Primeiras Letras como uma de suas premissas na concessão de privilégios e imposição de deveres.

\section{Referências}

A EPOCHA. Folha política, comercial e noticiosa. Belém, 1 de março de 1859: Typographia do observador, 1859a. Anno II. № 12.

A EPOCHA. Folha política, comercial e noticiosa. Belém, 26 de Abril de 1859: Typographia do observador, 1859b. Anno II. № 148.

ALVES FILHO, Aluizio. Aspetos políticos e administrativos da formação e consolidação do Estado nacional brasileiro (1808-1889). Rev. Portuguesa e Brasileira de Gestão, Lisboa, v. 8, n. 1, p. 100-110, mar. 2009. Disponível em http://www.scielo.mec.pt/scielo.php?script=sci_arttext\&pid=S1645-

$44642009000100011 \&$ lng=pt\&nrm=iso. Acesso em 20 mar. 2018.

BIBLIOTECA NACIONAL DIGITAL BRASIL. Hemeroteca Digital Brasileira. Disponível em: http://memoria.bn.br/hdb/periodico.aspx. Acesso em: 30/03/2015

BRASIL. Carta de Lei de 25 de Março de 1824. Constituição Política do Império do Brasil, elaborada por um Conselho de Estado e outorgada pelo Imperador D. Pedro I, em 25.03.1824. Rio de Janeiro: Secretaria de Estado dos Negócios do Império do Brasil a fls. 17 do Liv. 4ํ de Leis, Alvarás e Cartas Imperiais, 1824. Disponível em: http://www.planalto.gov.br/ccivil_03/constituicao/constituicao24.htm. Acesso em: 31/03/2015.

BRASIL. D. Pedro I. Manda criar escolas de primeiras letras em todas as cidades, vilas e lugares mais populosos do Império. Lei de 15 de outubro de 1827. Disponível em: http://www.planalto.gov.br/ccivil_03/leis/LIM/LIM-15-10-1827.htm. Acesso em: 06/04/2015.

BRASIL. Lei no 16 de 12 de agosto de 1834. Faz algumas alterações e addições á Constituição Politica do Imperio, nos termos da Lei de 12 de Outubro de 1832". Disponível em: http://www.planalto.gov.br/ccivil_03/leis/lim/LIM16.htm. Acesso em 23.05.2019. 


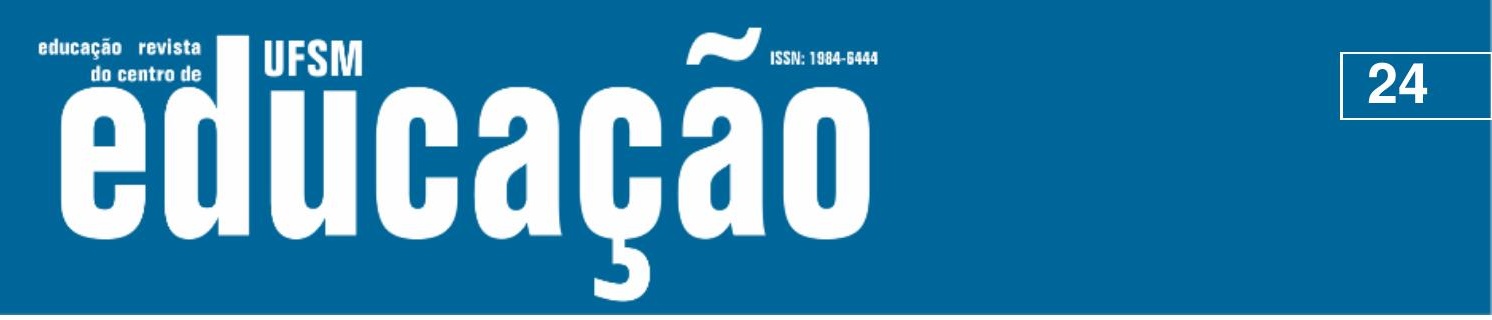

ISSN: 1984-6444 | http://dx.doi.org/10.5902/1984644435456

BRASIL. D. Pedro II. Coleção das decisões do Governo do Império do Brasil (1834). Rio de Janeiro. Typographia Nacional, 1834.

CÂMARA DOS DEPUTADOS. Coleção das Leis do Império do Brasil. Disponível em: http://www2.camara.leg.br/atividade-legislativa/legislacao/publicacoes/doimperio. Acesso em: 01/04/2015.

CARDOSO, Sergio Ricardo Pereira. A educação paraense na primeira metade do século XIX: com a palavra, Antônio Ladislau Monteiro Baena. Momento, ISSN $0102-$ 2717, v. 25, n. 2, p. 19-36, jul./dez. 2016.

CASTANHA, André Paulo. O Ato Adicional de 1834 na história da educação brasileira. Revista Brasileira de História da Educação. $n^{\circ} 11$ jan./jun. 2006. Disponível em: http://periodicos.uem.br/ojs/index.php/rbhe/article/view/38639/20170. Acesso em 23.05.2019.

CENTER FOR RESEARCH LIBRARIES. Global Resources Network. Brazilian Governament Documents. Disponível em: http://www-apps.crl.edu/brazil. Acesso em: $30 / 3 / 2015$.

CORRÊA, Paulo Sérgio de Almeida. Instituição e consolidação do campo da História da Educação nos Grupos de Pesquisa situados na Região Norte do Brasil: refutação à tese da insignificância. Revista HISTEDBR On-line, v. 13, p. 71-96, 2013. Disponível em: http://www.fae.unicamp.br/revista/index.php/histedbr/article/viewFile/5340/4288. Acesso em: 30/03/2015.

COSTA, J. C. C.; ANANIAS, Mauricéia; ARAÚJO, R. M. S. (Orgs.). Temas sobre a instrução no Brasil imperial (1822-1889). João Pessoa: Marca de Fantasia, 2014.

COSTA, Renato Pinheiro da; CORREA, Paulo Sérgio de Almeida. Fontes históricas no contexto da historiografia dos Grupos Escolares. In: IX Seminário Nacional de Políticas Públicas Educacionais e Currículo, 2010, Belém. Expansão da PósGraduação em Educação e a Formação Axiológica dos Pesquisadores: Dimensões Ético-Político-Epistemológicas, 2010.

COSTA, Renato Pinheiro da. A institucionalização do ensino no Estado do Pará e as reformas educativas materializadas nos grupos escolares. In: IX Jornada HISTEDBR, 2010, Belém. Jornada HISTEDBR. Belém: HISTEDBR, 2010. v. 1. Disponível em: http://www.histedbr.fe.unicamp.br/acer_histedbr/jornada/jornada9/_files/KkjZXdD.doc . Acesso em: 06/04/2015.

DALLARI, Dalmo de Abreu. Elementos de teoria geral do Estado. 21a․ ed. São Paulo: Saraiva, 2000. 307 p.

DAMASCENO, Alberto. Espadas, terços e letras: origens da educação estatal na América Portuguesa. Belém: Editora Açaí, 2012. 


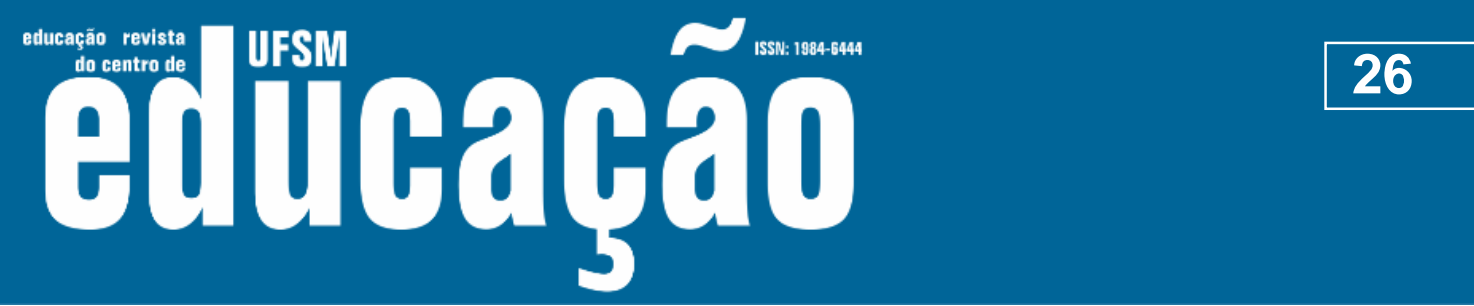

ISSN: 1984-6444 | http://dx.doi.org/10.5902/1984644435456

MARTINS, Angela Maria Souza. Breves reflexões sobre as primeiras escolas normais no contexto educacional brasileiro, no século XIX. VIII Seminário Nacional de Estudos e Pesquisas. "História, Sociedade e Educação no Brasil". História, Educação e Transformação: tendências e perspectivas. 30 de junho a 03 de julho de 2009. Disponível em: https://histedbrnovo.fe.unicamp.br/pfhistedbr/seminario/seminario8/_files/tsc_angela.pdf

MENDONÇA, Camila Técla Mortean; COSTA, Maria Luisa Furlan. A educação no Império brasileiro: o método Lancaster. Anais Eletrônico IX EPCC - Encontro Internacional de Produção Científica UniCesumar Nov. 2015, n. 9, p. 4-8 ISBN 97885-8084-996-7 IX EPCC - Encontro Internacional de Produção Científica UniCesumar 03 a 06 de novembro de 2015 Maringá - Paraná - Brasil. Disponível em: http://www.cesumar.br/prppge/pesquisa/epcc2015/anais/camila_tecla_mortean_men donca_1.pdf. Acesso em:23.05.2019.

MONTALVÃO, Sérgio. Educação na ordem constitucional brasileira: da monarquia à república. Revista Contemporânea de Educação N $\cong 11$ - janeiro/julho de 2011. Disponível em: http://www.fe.ufrj.br/artigos/n11/educacao_monarquia_republica.pdf. Acesso em 30.08.2018.

MOTA, Carlos Guilherme (Org.). Viagem incompleta: A experiência brasileira (15002000). São Paulo: Editora SENAC, 2000.

NERY, Vitor S. C.; FRANCA, Maria do P. S. A. Disseminação da instrução pública primária na província do Pará na década de 1870. João Pessoa: Temas em Educação (UFPB), v. 23, p. 82-100, 2014. Disponível em: http://periodicos.ufpb.br/ojs/index.php/rteo/article/view/20906/12563. Acesso em: 30/03/2015.

NOGUEIRA, Octaciano. Constituições Brasileiras: 1824. Brasília: Senado Federal, Secretaria de Edições Técnicas, 2012.

NUNES, Francivaldo Alves. Entre máquinas, insumos e treinamentos: Escola Rural Pedro II e o combate à agricultura rotineira no Pará (anos de 1860). In: MELO, Clarice Nascimento de; FRANÇA, Miria do Perpétuo Socorro Gomes de Souza Avelino de (Orgs.). História da Educação no Pará. Belém: EDUEPA, 2014. p. 41-58.

OLIVEIRA, Rúbia Nazari. Do estado moderno ao Estado Constitucional - algumas considerações. Revista Eletrônica Direito e Política, Itajaí, v. 1, n. 1, 3ํquadrimestre de 2006. Disponível em: wwwunivali.br/direitoepolitica

PARÁ, Arquivo Público do Estado do Pará. Coleção de leis da Província do Grão Pará de1835 a 1845 . Tomo VI - 1843 - Parte I.

PARÁ. Bernardo de Souza Franco. Presidente da Província do Gran-Pará na Occazião da abertura da Assembléia Legislativa Provincial. Belém: Typographia de Santos \& menor, 1839. 


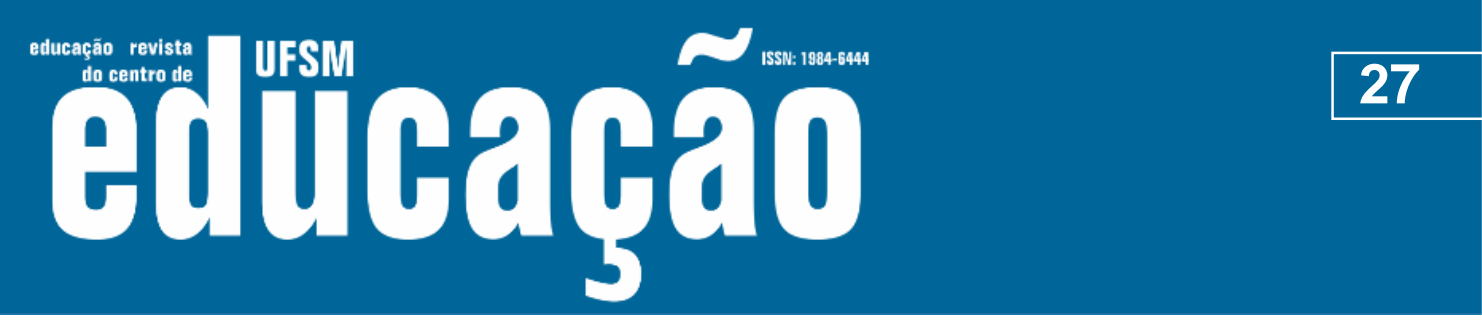

ISSN: 1984-6444 | http://dx.doi.org/10.5902/1984644435456

PARÁ. Governador, 1851. (Presidente - Fausto Augusto D’Aguiar). Lei no 203 de 27 de outubro de 1851. Belém: Typ. Commercial de A. J. R. Guimarães, 1851.

PARÁ. Governador, 1859. Fala dirigida á Assembléia Legislativa da Província do Pará na segunda sessão da XI legislatura pelo exm.o sr. tenente coronel Manoel de Frias e Vasconcellos, presidente da mesma Província, em 1 de outubro de 1859. Pará, Typ. Commercial de A. J. R. Guimarães, 1859.

RIBEIRO, Paulo Rennes Marçal. História da educação escolar no Brasil: notas para uma reflexão. Paidéia (Ribeirão Preto) [online]. 1993, n.4, pp. 15-30. ISSN 0103-863X. http://www.scielo.br/pdf/paideia/n4/03.pdf

SALOMÃO, Ivan Colangelo. Influências do positivismo na formação do pensamento desenvolvimentista brasileiro. Revista Econômica, volume 18, número 1, jun.2016. Disponível em file://C:/Users/Microsoft/Downloads/258-1075-1-PB.pdf Acesso em 22.08.2018.

SANTOS, Boaventura de Sousa. Pela mão de Alice: o social e o político na pósmodernidade. Coimbra: Almeida, 2013.

SAVIANI, Dermeval. História das ideias pedagógicas no Brasil. Campinas: Autores Associados, 2008.

SAVIANI, Dermeval. Instituições escolares: conceito, história, historiografia e prática. Cadernos de História da Educação - no. 4 - jan./dez. 2005. Disponível em: http://www.seer.ufu.br/index.php/che/article/view/382/363. Acesso em: 24.05.2017.

SILVA, Mozart Linhares da. Do império da lei às grades da cidade. Porto Alegre: EDIPUCRS, 1997.

SOUZA, Celita Maria Paes de. Traços de compaixão e misericórdia na história do Pará: instituições para meninos e meninas desvalidas no século XIX até início do século XX. Tese (Doutorado em Educação: Currículo). Pontifícia Universidade Católica de São Paulo, PUC-SP. Ano de Defesa: 2010.

SOUZA, Celita Maria Paes de. Colégio Nossa Senhora do Amparo: educação feminina no Século XIX na história do Pará. In: MELO, Clarice Nascimento de; FRANÇA, Miria do Perpétuo Socorro Gomes de Souza Avelino de (Orgs.). História da Educação no Pará. Belém: EDUEPA, 2014. p. 15-39.

STEPHANOU, Maria; BASTOS, Maria Helena Câmara (Orgs.). História e memória da educação no Brasil. Vol. III: Século XX. Petrópolis, RJ: Vozes, 2012.

TAVARES, Maria Goretti da Costa. A formação territorial do espaço paraense: dos fortes à criação de municípios. Revista ACTA Geográfica, ANO II, n³, jan./jun. de 2008. p.59-83.

VASCONCELOS, Diego de Paiva. O liberalismo na constituição brasileira de 1824. Dissertação (mestrado) - Universidade de Fortaleza, 2008. 


\section{Usm Futlbap̧a}

ISSN: 1984-6444 | http://dx.doi.org/10.5902/1984644435456

VASCONCELOS, Helena Correa; OLIVEIRA, Ilda E. A. de; COSTA, Maria das Graças Pinheiro. A formação do professor para a escola básica no Pará. Belém: UFPA, 1992.

VIANNA, Arthur. Esboço retrospectivo da instrucção publica no Pará. In: A educação no Pará. Documentário. Belém/PA. Governo do Estado do Pará: Secretaria de Estado de Educação, 1987.

VIDAL, Diana Gonçalves; HILSDORF, Maria Lúcia Sepedo (Orgs.). Brasil 500 Anos: Tópicos da História da Educação. São Paulo: Editora da Universidade de São Paulo, 2001.

ZOTTI, Solange Aparecida. Organização do Ensino Primário no Brasil: uma leitura da história do currículo Oficial. 2006. Disponível em: http://www.histedbr.fe.unicamp.br/navegando/artigos_frames/artigo_102.html.

Acesso em: maio 2019.

\section{Correspondência}

Paulo Sérgio de Almeida Corrêa - Universidade Federal do Pará - Rua Augusto Corrêa 01, Cidade universitária, Setor de Recreação. CEP: 66075-110, Guamá, Belém, Pará, Brasil.

Renato Pinheiro da Costa - Travessa Júlio Marques, 1258. Bairro Ibiza. CEP: 68736783. Altamira, Pará, Brasil.

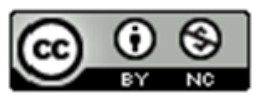

This work is licensed under a Creative Commons Attribution-NonCommercial 4.0 International (CC BY-NC 4.0)

\section{Notas}

\footnotetext{
${ }^{1}$ A gênese histórica desse Município remonta ao ano de 1754, quando se formou o primeiro núcleo populacional. Após sua decadência, a Freguesia foi restaurada no ano de 1839, quando ainda era subordinado ao Município de Igarapé-Miri, mas "em 1856, a localidade foi elevada à Vila e município, cuja instalação deu-se, em 1871. Porém, em virtude de dissenções políticas ocorridas nos períodos monárquico e republicano, o município veio a ser extinto nos anos de 1887, 1904 e 1930, até que, em 1935, readquiriu, definitivamente, a sua emancipação políticoadministrativa" (IBGE. https://biblioteca.ibge.gov.br/visualizacao/dtbs/para/moju.pdf. Acesso em 24.08.2018).

${ }^{2}$ Câmara dos Deputados. Coleção das Leis do Império do Brasil.
} 


\section{N

ISSN: 1984-6444 | http://dx.doi.org/10.5902/1984644435456

${ }^{3} \mathrm{http} / / /$ www2.camara.leg.br/legin/fed/lei_sn/1824-1899/lei-38398-15-outubro-1827-566692-publicacaooriginal90222-pl.html

${ }^{4}$ Pelas informações apresentadas no Livro de Tombo da Paróquia do Divino Espírito Santo (1952), registro mais antigo a que se tem acesso, a Vila de Moju foi constituída ainda no século XVIII, período da colonização brasileira, com um rio que segue a extensão do município que, à época, servia de principal via de comunicação com a capital do então Estado do Grão-Pará, distante $65 \mathrm{~km}$ em linha reta. É importante mencionar que, por serem tempos em que as tecnologias de comunicação - como estradas e pontes - não estavam construídas na região, o rio Moju era a principal rota por onde se fazia o transporte de pessoas e mercadorias de Belém a Manaus, passando por outras vilas importantes, através do barco a vapor Companhia do Amazonas.

${ }^{5}$ A Epocha foi um jornal de circulação na Província do Pará, que iniciou seus trabalhos no ano de 1858, trazendo notícias sobre comércio, política e comunicados de decretos da Presidência da Província.

${ }^{6}$ Vale a pena fazer a ressalva que, no texto do jornal A Epocha, a lei é de $n^{\circ} 293$ de 27 de outubro de 1851, no entanto, nos relatórios de Presidente da Província, ela está sob o n ${ }^{\circ} 203$ do mesmo ano.

${ }^{7}$ Segundo Mendonça e Costa (2015. p. 1), "O método Lancaster surgiu na Europa no final do século XVIII, seu precursor foi o inglês Joseph Lancaster (1778-1838), amparado nas ideias pedagógicas do pastor anglicano Andrew Bell (1753-1832)". Sua operacionalização pedagógica "consiste na utilização de alunos-monitores para o ensino da leitura, ou seja, os alunos que se destacam são chamados a serem alunos-monitores e passam a ensinar um grupo de alunos. No Brasil, este método foi inserido no período do império que ocorreu entre 1822 a 1889, por meio da Lei de 15 de outubro de 1827, a qual previa a inserção deste método para o ensino das primeiras letras". 